\title{
A primary school active break programme (ACTI-BREAK): study protocol for a pilot cluster randomised controlled trial
}

\author{
Amanda Watson *iD, Anna Timperio, Helen Brown and Kylie D. Hesketh*
}

\begin{abstract}
Background: Levels of overall physical activity have been shown to decline across childhood. Schools are considered ideal settings to promote physical activity as children spend a large amount of their waking hours at school. Time-efficient physical activity strategies that demonstrate a positive impact on academic-related outcomes are needed to enable physical activity to be prioritised in the school day. The ACTI-BREAK programme requires classroom teachers to integrate active breaks; 5 -min bursts of moderate-intensity physical activity into their classroom routine. Active breaks have been shown to be effective in improving academic-related outcomes, a potentially appealing aspect for teachers and schools. The primary aim of this study is to assess the feasibility and potential efficacy of the ACTI-BREAK programme on children's academic achievement. Secondary aims are to explore the impact of ACTI-BREAK on children's on-task behaviour and objectively measured physical activity levels.

Methods: ACTI-BREAK is a 6-week, classroom-based, physical activity intervention. This pilot trial of the programme will be evaluated using a cluster randomised controlled design. Government primary schools in metropolitan Melbourne, Australia will be invited to participate in the programme in 2017. Randomisation will occur at the school level, with the aim to recruit six schools (three intervention and three control). The ACTI-BREAK programme is theoretically grounded, and was developed with input and guidance from current primary school teachers. Teachers from the intervention schools will receive a 45-min training session and be asked to incorporate ACTI-BREAKS into their classroom routine three times per day for 6 weeks. Intervention support will be provided via assisted delivery. The primary outcomes will be children's academic achievement in mathematics and reading. Children's on-task behaviour and school-day physical activity will be assessed as secondary outcomes. Process evaluation will also be carried out.
\end{abstract}

Discussion: The ACTI-BREAK programme has been designed to be a time-efficient, feasible and appealing approach to physical activity promotion for schools. This study will assess required teacher time commitment and the potential for the ACTI-BREAK programme to improve academic-related outcomes and school-day physical activity levels with the potential for a full-scale trial in the future.

Trial registration: Australia New Zealand Clinical Trials Registry, identifier ACTRN12617000602325. Retrospectively registered on 27 April 2017.

Keywords: Physical activity, School, Classroom, Academic outcomes, Children, Intervention, Protocol

\footnotetext{
* Correspondence: watson@deakin.edu.au; kylie.hesketh@deakin.edu.au Institute for Physical Activity and Nutrition (IPAN), School of Exercise and Nutrition Science, Deakin University, Geelong, VIC, Australia
} 


\section{Background}

While the health benefits of physical activity are well established [1], higher levels of physical activity are also associated with enhanced academic-related outcomes including cognitive function, classroom behaviour and academic achievement [2-4]. However, population based-studies have reported that over $50 \%$ of children in Australia and internationally are not meeting the recommended levels of physical activity, and rates of compliance decline with increasing age from the early primary school years [5-8]. Thus, increasing children's levels of physical activity has important implications for both health and academic-related outcomes during childhood. The brain may be particularly sensitive to the effects of physical activity during preadolescence as the neural circuitry of the brain is still developing [9]. Thus, in order to stem age-related declines in physical activity and maximise academic-related outcomes, pre-adolescent children aged 8 to 10 years were selected as the target population for this study.

Primary schools can provide an ideal setting for the promotion of children's physical activity due to the amount of time children spend in this setting [10]. However, allocating more time for physical activity during the school day can be problematic due to competing curriculum demands. Thus, to enable physical activity to be prioritised in the school day, time-efficient physical activity strategies that benefit academic achievement are needed [11]. One solution could be to break up sedentary time with lightintensity physical activity (e.g. through the use of standing desks). A recent (2016) systematic review investigated the impact of standing desk interventions within the classroom ( $n=11$ studies). While results showed that standing desks within the classroom were not detrimental to children's academic-related outcomes ( $n=3$ studies) [12], more consistent positive associations have been observed for the effect of physical activity of at least moderateintensity on academic outcomes [13]. Thus, combining breaks in sedentary time with moderate-intensity physical activity is hypothesised to have enhanced benefits on academic-related outcomes. Active breaks, requiring classroom teachers to integrate short bursts of physical activity into their classroom routine $[14,15]$, may provide such a more effective approach.

Active breaks have been shown to be effective in improving children's academic achievement [16, 17], classroom behaviour (e.g. on-task behaviour) [14, 15, 18, 19], and cognitive function (e.g. attention) [20, 21]. Thus, active breaks can provide a potentially appealing physical activity promotion strategy for teachers and schools. However, there are several factors associated with their practical application. During qualitative interviews with teachers about their perceptions of using active breaks in the classroom, teachers explained the need for active breaks to cater for time (e.g. due to academic accountability) and space constraints [11,
22]. Thus, teachers preferred active breaks that were quick and easy to implement (i.e. require no set-up or equipment) and that were able to be performed within the limited available space in the classroom $[11,22]$. Teachers also expressed concern that active breaks would have an adverse effect on classroom behaviour [11, 22]. Thus, time and space constraints should be considered when developing classroom-based active break programmes, and the potential for active breaks to improve on-task classroom behaviour should be highlighted during teacher training sessions.

There are several limitations with existing active break programmes. No evidence-based active break intervention to date has involved classroom teachers in the development of the intervention [23]. This has important implications for the feasibility and sustainability of such programmes outside of the research context [4]. Many existing programmes require active break durations of between 10 and $15 \min$ [19, 21, 24-26]. However, qualitative interviews with teachers about their satisfaction with a previous active break programme indicated that active breaks longer than $5 \mathrm{~min}$ were unlikely to be adopted due to time constraints [27]. This discrepancy between evidence and practice highlights the importance of involving teachers in the development phase to ensure that interventions have real-world applicability.

While the existing evidence base suggests that active breaks need to last at least $10 \mathrm{~min}$ and be of at least moderate physical activity intensity in order to be effective for improving academic-related outcomes [15, 16], few studies (two interventions) have investigated the effect of active breaks shorter than $10 \mathrm{~min}$ on academic-related outcomes, and results were inconsistent [14-16, 20]. Further, the shorter duration active breaks in these interventions were implemented once per day. A recent (2016) study showed that children aged 10 to 13 years who performed two 20-min moderate-intensity active breaks per day had significantly better selective attention scores compared to children who performed one active break per day [28], highlighting the potential effectiveness of frequent active breaks. However, the impact of frequent, short (i.e. 5-min), active breaks on academic-related outcomes is unknown, and further research is needed to determine if this more feasible approach can be effective in improving academic-related outcomes.

A further limitation of previous research in this area is the choice of outcome assessment measures. Most studies have used standardised tests or grades to assess intervention effects on academic achievement [29-31]. Although helpful in assessing long-term impacts (i.e. yearly) these measures are not sensitive to short-term academic progress [32]. Given that most active break interventions have been implemented over relatively short durations (6 weeks to 8 months) [17, 30, 33], important intervention effects on academic achievement may have 
been missed. One way of assessing academic achievement over the short term is through curriculum-based measures [34]. Curriculum-based measures are commonly used by teachers to assess progress in key curriculum areas (e.g. mathematics and reading) over the short term [35]. These tools are sensitive to small changes in academic achievement, and can be administered frequently (e.g. weekly) [34] and therefore, may be a more appropriate measure for intervention periods of less than 1 year. It may be important for active break programmes to demonstrate positive effects on academic achievement, especially in the areas of mathematics and language (e.g. reading), as these test results are often used for the evaluation of schools [36].

Lastly, the majority of active break studies either did not measure intervention effects on physical activity, or used pedometer measures [31], which do not provide an accurate measure of physical activity intensity. To the authors' knowledge, only one active break study has used an objective measure of physical activity intensity to determine effects on moderate- to vigorous-intensity physical activity levels [18]. Results showed that students in classrooms where teachers reported implementing active breaks in the past week were more likely to obtain $30 \mathrm{~min}$ per day of moderate- to vigorous-intensity physical activity during the school day (odds ratio $(\mathrm{OR})=1.75 ; p=0.002$ ) than children in classrooms where active breaks were not implemented [18]. However, that study measured physical activity on a subsample of participants only [18]; thus, results may not be generalisable to all children in the class. The ACTIBREAK programme was developed to address limitations in previous studies including lack of teacher involvement in the development phase, the use of academic outcome assessment measures designed to assess long-term change in short-term interventions, and the lack of objective physical activity measurement.

\section{Aims}

The primary aim of this study is to assess the feasibility and potential efficacy of a 6-week, pilot, classroom-based, physical activity intervention (ACTI-BREAK programme) on achievement in mathematics and reading in children in years 3 and 4 (aged approximately 8 to 10 years) attending primary (elementary) school in Melbourne, Australia. The impact of ACTI-BREAK on children's on-task classroom behaviour and objectively measured school-day physical activity levels will be explored as secondary aims.

\section{Methods}

\section{Study design}

A pilot cluster randomised controlled trial will evaluate the ACTI-BREAK programme compared with a waitlist control. The design, conduct and reporting of the ACTIBREAK programme will adhere to the Consolidation
Standards of Reporting Trials (CONSORT) guidelines, and is guided by the Standard Protocol Items: Recommendations for Interventional Trials (SPIRIT) Statement. Additional file 1 shows the completed SPIRIT Checklist (see Additional file 1). Figure 1 provides an overview of the schedule for enrolment, interventions and assessments (SPIRIT Figure) and Fig. 2 shows a diagram of participant flow through the study. Principals, teachers, and parents will need to provide written informed consent to participate in the study. Ethical approval has been attained from Deakin University Human Research Ethics Committee, Melbourne, Australia (2016-020) and the Victorian Department of Education and Training (2016-002962).

\section{Power calculation}

The detectable difference, based on grade-based benchmarks for year-3 reading scores in the Wheldall Assessment of Reading Passages (WARP) test [37] at mid-year, and 12 clusters (classes) per group, each with nine students, is 23.55 points in reading achievement with power set to $80 \%$. Based on results from this study effect sizes will be generated to inform the sample size needed for a full-scale trial.

\section{Study setting}

Government primary schools located within a $30-\mathrm{km}$ radius of Deakin University and with a Victorian Socio-economic Indexes for Areas (SEIFA) Index of relative socio-economic advantage and disadvantage deciles of 4,5 , or 6 , representing middle socio-economic position (SEP) will be invited to participate. Middle SEP government schools were chosen for this study as children attending these schools represent a large number of primary school children in Australia, making results likely to be generalisable to a large number of schools and children. Students attending Victorian government schools spend approximately $6.5 \mathrm{~h}$ per day at school (9.00 a.m. to 3.30 p.m.), and have a short recess/ snack break (approximately $30 \mathrm{~min}$ ) and a longer lunch break (approximately $1 \mathrm{~h}$ ). The intervention will target year- 3 and -4 classes (aged approximately $8-10$ years). For schools to be eligible, they must have straight or composite year-3 and year-4 classes. Schools where composite classes mixed year-3 and year-4 students with other grades (e.g. years $2 / 3$ or years $4 / 5$ composites) were not eligible. Based on a $37 \%$ response rate (as demonstrated in a similar study conducted in the Australian school context [38]) and an average class size in Victorian schools of 23 students per class [39], we anticipate that nine students per class will consent to take part in this pilot study. For feasibility reasons, the intention is to recruit six schools (three intervention and three control) from which a sample size of 216 children is estimated (six schools $\times$ four classes (two classes per year level) [40] $\times$ nine students). 


\begin{tabular}{|c|c|c|c|c|c|}
\hline & Enrolment & Allocation & Baseline & Intervention & Close-out \\
\hline TIMEPOINT & $-t_{1}$ & $\mathbf{0}$ & $t_{1}$ & $t_{2}$ & $t_{3}$ \\
\hline \multicolumn{6}{|l|}{ ENROLMENT: } \\
\hline Informed consent & $\mathrm{X}$ & & & & \\
\hline Allocation & & $\mathrm{X}$ & & & \\
\hline \multicolumn{6}{|l|}{ INTERVENTIONS: } \\
\hline \multicolumn{6}{|l|}{ ACTI-BREAK } \\
\hline \multicolumn{6}{|l|}{ ASSESSMENTS: } \\
\hline Mathematics & & & $\mathrm{X}$ & & $\mathrm{X}$ \\
\hline \multirow{3}{*}{ Classroom behaviour } & & & $\mathrm{X}$ & & $\mathrm{X}$ \\
\hline & & & $\mathrm{X}$ & $\mathrm{X}$ & $\mathrm{X}$ \\
\hline & & & $\mathrm{X}$ & $\mathrm{X}$ & $\mathrm{X}$ \\
\hline
\end{tabular}

Fig. 1 Standard Protocol Items: Recommendations for Interventional Trials (SPIRIT) Figure

\section{Recruitment of schools}

Principals from eligible schools will be invited to participate initially via email, and then contacted via telephone 1 week later. A researcher (AW) will meet with all interested principals to explain the requirements of study participation. Principals who agree to their school participating in the study will be provided with a plain language statement and consent form to be signed and returned prior to participation.

\section{Recruitment of participants}

Once consent is obtained from school principals, written consent for participation will be obtained from teachers of year-3 and year-4 classes. Then, all year- 3 and year-4 children at participating schools will be provided with an information pack containing a plain language statement and consent form to be given to their parents or guardians to provide consent for the child's participation. As the school will have consented to the programme being delivered to all year-3 and year-4 children, and the programme will be delivered by classroom teachers as part of their daily classroom activities, consent from parents will only be required for the evaluation components of the study. Thus, all children in participating classes will join in the ACTI-BREAKS; however, data will only be collected from children with parental consent as part of the evaluation of ACTI-BREAKS. Further, so that no child feels excluded, all children in participating classes will be invited to participate. However, data from children with diagnosed behavioural or learning problems (e.g. attention-deficit hyperactivity disorder (ADHD)) will be excluded from analyses. The schools, teachers and children will not be paid to participate in the ACTI-BREAK programme.

\section{Randomisation}

Schools will be randomised at the school level (to avoid potential for contamination) to either the intervention or waitlist control group, prior to baseline assessments. The waitlist control group will be provided with the intervention materials after the final data collection period. Randomisation will be carried out via computergenerated random number sequence by a researcher who has no contact with the schools or participants. As all schools will be from middle socioeconomic position areas within a similar geographical location, it is unlikely for there to be large differences in baseline characteristics, including academic achievement levels. Any differences between the intervention and control groups will be by chance [41], and adjusted for in the analyses.

\section{Intervention \\ Development}

The ACTI-BREAK programme was informed by a review of the relevant academic literature and consultation with current primary school teachers. This study embeds the Capability, Opportunity, Motivation-Behaviour (COM-B) model [42], and is underpinned by Social Cognitive Theory (SCT) [43] and the Ecological Model (EM) (see Table 1). Nine teachers from schools demographically similar to the intervention schools were interviewed about the feasibility of introducing regular active breaks into primary school classrooms. Of those teachers, most $(n=6)$ had experience using active breaks in their classroom. Topics covered included preferred duration, intensity and frequency of active breaks, as well as potential barriers and facilitators to implementation. Teachers considered frequent (multiple times per day), 5-min active breaks feasible, and anything longer 


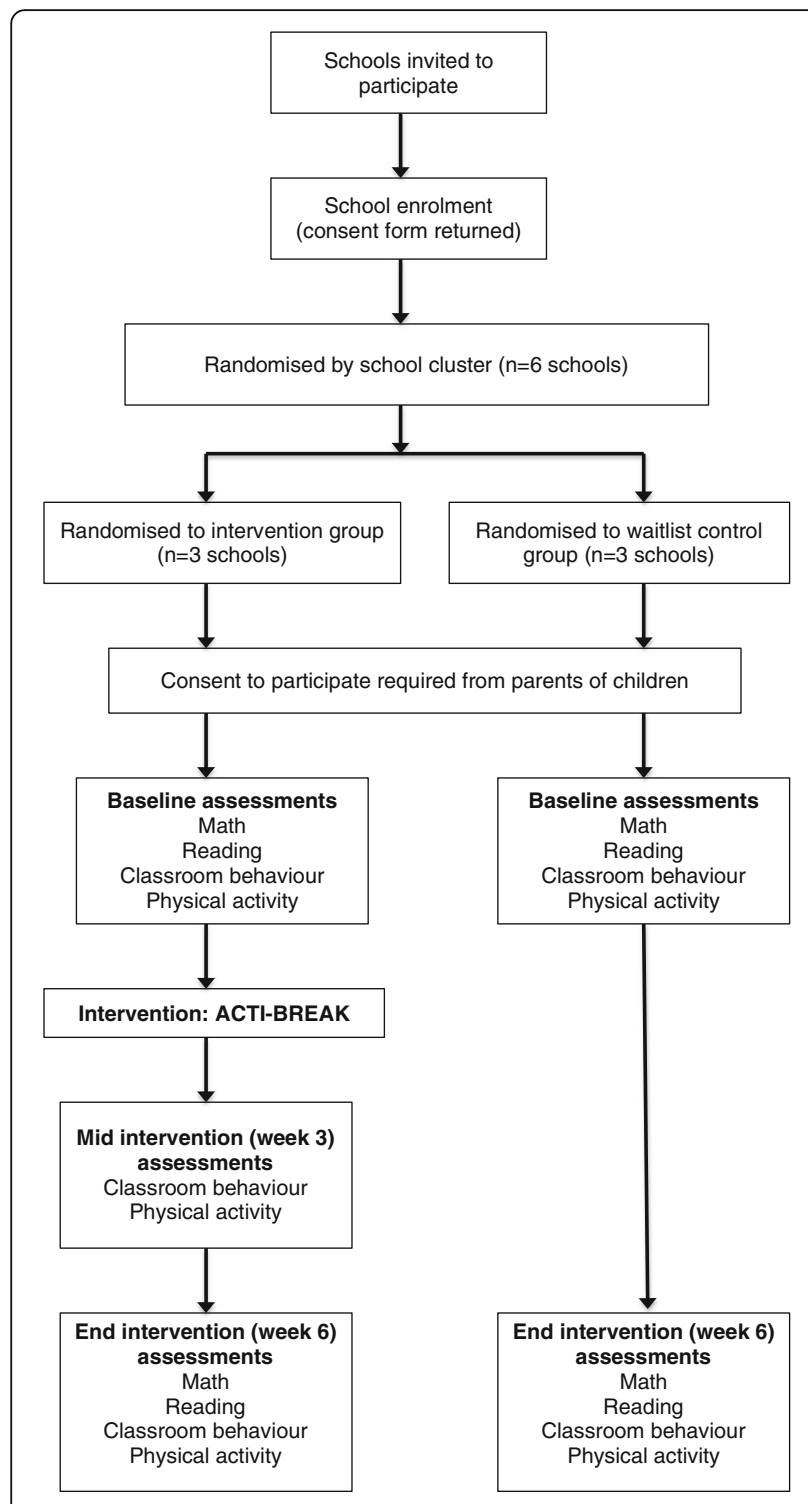

Fig. 2 Flow diagram of participants through the ACTI-BREAK study

than 5 min was deemed unlikely to be adopted by teachers. Further, teachers preferred moderate-intensity as opposed to vigorous-intensity active breaks which they considered to be disruptive (due to students needing to get drinks and take off sweaters). Given this and the support for the role of moderate-intensity active breaks for improving academic-related outcomes in the academic literature $[19,21,28]$, the ACTI-BREAK activities were selected to be of moderate physical activity intensity. During the programme development phase, teachers also communicated that it would be important to have a range of different active break activities from which they could select activities that best engaged their class and to allow for variety. Thus, the actual activities undertaken will differ by class; however, all activities are designed to be of moderate intensity. An important element of the ACTI-BREAK programme is that the activities do not require any set-up and only use equipment already available in classrooms (e.g. music), as in the programme development consultation teachers consistently expressed the need for active breaks to be quick and easy to adopt. Lastly, teachers stated that the scheduling of ACTI-BREAKS will need be determined by individual teachers due to variations in timetables across schools and classes (e.g. due to specialist subjects).

\section{The ACTI-BREAK programme}

The ACTI-BREAK programme will involve teachers implementing 5-min active breaks, three times daily in their classrooms for 6 weeks, using activities adapted from a variety of sources [44-47]. Permission to use and modify these activities was sought and attained from the authors (personal communication). The ACTI-BREAK activities are age-appropriate and include a variety $(n=$ 30) of active break options with suggested modifications for easier or more challenging activities. ACTI-BREAK activities incorporate drama (e.g. jog on the spot as if a big scary bear is chasing you), games (e.g. musical chairs), following instructions (e.g. when the music stops, touch 10 chairs in a row), and technology/websites (e.g. GoNoodle and YouTube). Examples of ACTIBREAK activities can be found in Table 2. A 6-week trial was chosen for the initial assessment of programme feasibility based on pragmatic reasons as it allows the trial to be completed within a single school term (including teacher training and baseline assessments pre trial, as well as teacher and student qualitative feedback post trial). Further, the academic literature shows that intervention periods as short as 3 weeks may be sufficient duration to see benefit to academic-related outcomes $[14,20]$.

To improve adherence to the intervention protocols, the intervention will be implemented using assisted delivery. Week 1: a researcher (AW) and the classroom teacher will implement the ACTI-BREAKS together; week 2: the classroom teacher will implement the ACTIBREAKS with the researcher observing and providing feedback; week 3 onwards: the classroom teacher will deliver the ACTI-BREAKS on their own with the researcher not present. The researcher will provide teachers with general encouragement and support during visits to schools to fit and collect activity monitors and carry out academic assessments. Further, teachers will be able to email or call the researchers at any time if they have concerns or require further support.

\section{Teacher training session}

At each intervention school, all teachers of years 3 and 4 will participate in a one-off 45 -min face-to-face training 
Table 1 Theoretical basis of the ACTI-BREAK programme

\begin{tabular}{|c|c|c|}
\hline Constructs & Behaviour-change technique & Example in intervention \\
\hline \multicolumn{3}{|l|}{ During teacher training } \\
\hline \multicolumn{3}{|l|}{ Individual } \\
\hline Skills/capability & $\begin{array}{l}\text { * Demonstration of behaviour } \\
\text { * Practice behaviour } \\
\text { * Provide feedback }\end{array}$ & $\begin{array}{l}\text { * During the teacher training session and assisted rollout phase the intervention } \\
\text { teachers will be provided with demonstrations of a range of ACTI-BREAK activities } \\
\text { * Researcher assisted rollout during weeks } 1 \text { and } 2 \text { of the intervention }\end{array}$ \\
\hline Outcome expectations & * Provide information & $\begin{array}{l}\text { * Teacher training session provides information on academic-related benefits of } \\
\text { active breaks }\end{array}$ \\
\hline Support & * Information about others' approval & $\begin{array}{l}\text { * Share anonymous feedback from teachers who have used active breaks in their } \\
\text { classroom obtained during the qualitative intervention development phase } \\
\text { (teacher interviews) }\end{array}$ \\
\hline \multicolumn{3}{|l|}{ During intervention } \\
\hline \multicolumn{3}{|l|}{ Individual } \\
\hline Enjoyment (students) & $\begin{array}{l}\text { * Provide opportunities to participate in } \\
\text { enjoyable physical activities }\end{array}$ & $\begin{array}{l}\text { * The ACTI-BREAK programme provides a variety of different active break options } \\
\text { for teachers and/or students to select from }\end{array}$ \\
\hline Goals & ${ }^{*}$ Goal setting & * Set goal to deliver $3 \times 5$-min ACTI-BREAKS per day \\
\hline Monitoring & * Self-monitoring of behaviour & $\begin{array}{l}\text { * During visits to schools (to fit and collect activity monitors and carry out academic } \\
\text { assessments), teachers will be prompted to complete the teacher log after each } \\
\text { ACTI-BREAK }\end{array}$ \\
\hline \multicolumn{3}{|l|}{ Interpersonal } \\
\hline Social support & * Provide general encouragement & $\begin{array}{l}\text { * During visits to schools to fit and collect activity monitors and carry out academic } \\
\text { assessments }\end{array}$ \\
\hline \multicolumn{3}{|l|}{ Environmental } \\
\hline Time & * Minimising time barrier & * All ACTI-BREAKS are quick and easy to implement \\
\hline Prompts & * Prompts/cues & $\begin{array}{l}\text { * A log will be placed on the whiteboard to remind teachers to do ACTI-BREAKS, } \\
\text { and teachers will ask students to hold them to account } \\
\text { * ACTI-BREAK activities will be printed on individual cards }\end{array}$ \\
\hline
\end{tabular}

session approximately 1 week prior to implementing the ACTI-BREAK programme. The session will be conducted on school grounds at a convenient time for teachers, and will be delivered by the researcher (AW) who is a qualified and experienced primary school teacher. The training session is designed to inspire and equip the teachers with the necessary skills and knowledge to be able to implement the ACTI-BREAK programme in their classrooms. This training session will include a rationale for adding active breaks to the classroom routine, current research evidence highlighting the potential positive effect of active breaks on academic-related outcomes, explanation of the ACTIBREAK programme and what they are required to do, and demonstrations of a range of the ACTI-BREAK activities. However, as the researcher will be delivering and observing the ACTI-BREAK programme during the first 2 weeks of implementation, extensive demonstrations of the active break activities will not be provided during the training session. At the completion of the training session, teachers will be provided with intervention materials including the ACTI-BREAK programme prompt cards, and classroom timers.

\section{Primary outcomes}

The primary outcome of academic achievement will be assessed using measures of reading and mathematical achievement. These assessments were chosen as the

Table 2 Example activities from the ACTI-BREAK programme

\begin{tabular}{|c|c|}
\hline ACTI-BREAK & Description \\
\hline I wonder if...? & $\begin{array}{l}\text { The teacher says 'I wonder if...?' And the students respond, 'What do you wonder?' The teacher then specifies } \\
\text { movement and the students perform that movement until the teacher says 'I wonder if...?' again. For example, } \\
\text { 'I wonder if students can walk backward without touching anyone or anything?' [44] }\end{array}$ \\
\hline As if & $\begin{array}{l}\text { The teacher reads a sentence to the class, and students act out each sentence for } 20 \text { to } 30 \text { s, e.g. 'jump in place } \\
\text { as if you're popcorn popping' [47] }\end{array}$ \\
\hline GoNoodle 'Guided Dancing' & $\begin{array}{l}\text { Go to the GoNoodle website and select the 'Guided Dancing' link, and select a video. Students follow along to } \\
\text { the characters on the screen. Some options include 'The Maxarena' (Macarena), 'Happy' (from Despicable Me) } \\
\text { and 'The Continental Drift' (Sid shuffle) from Ice Age [45] }\end{array}$ \\
\hline
\end{tabular}


primary outcomes for this study as these are the two key pillars by which teachers and schools assess academic progress [36].

\section{Reading achievement}

Reading achievement will be assessed using the WARP test [37]. This curriculum-based measure, designed for the Australian school context, is designed to track reading fluency of students in years 2 to 5 , and involves children reading for $1 \mathrm{~min}$ from a 200-word passage [37]. The number of words read correctly in that minute is a measure of the student's level of reading fluency [37]. Reading fluency has been shown to be a powerful predictor of reading performance, with meta-analytic results showing a strong correlation between curriculum-based measures of reading fluency and other standardised tests of reading performance $(r=0.67)$ [48]. The WARP test includes a set of three initial assessment passages and a set of 10 progress-monitoring passages [37]. On advice from the instrument author (personal communication), the progress-monitoring passages were chosen for the current study, as they can be expected to be sensitive to change over the 6-week intervention period. The 10 progress-monitoring passages correlate very highly to each other in terms of reading difficulty $(r=0.95-0.98)$ [49]. Thus, to eliminate potential learning effects, a different passage will be administered at baseline and end of the intervention, and is chosen based on advice from the author (personal communication). A researcher with a primary school teaching qualification and experience will administer this test individually to each student with parental consent, at baseline and during the final week (week 6) of the intervention.

\section{Mathematics achievement}

Achievement in mathematics will be assessed using the One-Minute Tests of Basic Number Facts, reproduced with permission from the Australian Council for Educational Research [50]. This tool consists of four One-Minute Basic Number Facts Tests [50], and is designed for the Australian school context. Each test has 33 items that focus on one of each of the following number operations: addition, subtraction, multiplication, and division [50]. This test has good test-retest reliability ( 0.88 to 0.94 depending on age level) [50]. To ensure alignment with the year-3 and year-4 curriculum early in the school year, and, therefore, potential to observe improvement, the subtraction test was chosen for this study. The addition test was not chosen due to the potential for ceiling effects, and thus limited potential to observe improvement. A researcher with a primary school teaching qualification and experience will administer this test to the whole class at baseline and at the end (week 6) of the intervention. Only data from students with parental consent will be used in the analyses. To accommodate class availability (e.g. due to specialist subjects) the reading and mathematics assessments will be carried out at a time that suits each classroom teacher.

\section{Secondary outcomes \\ On-task classroom behaviour}

Information will be collected on student on-task classroom behaviour at the individual level for those students with parental consent, and at the whole class level (no identifying information will be retained). As classroom behaviour can vary as a function of time of day, each class teacher will be required to record all observations of classroom behaviour at a consistent time each day. However, due to differing timetables across classes and schools, it will not be possible for all teachers to record behaviour observations at the same time of day.

Teachers at intervention and control schools will be required to observe behaviour during a 10-min observation period during a seated lesson at three time points at baseline and again at the end (week 6) of the intervention. In addition to baseline and the end of the intervention observations of behaviour, teachers at intervention schools will be required to record observations of behaviour during a 10-min observation period immediately before and immediately after participation in an ACTIBREAK at three time points during week 3 of the intervention. This pre-post measure will enable the acute effect of active breaks on classroom behaviour to be explored. Teachers will record observations of individual and group classroom behaviour simultaneously in order to limit the number of times that teachers will be required to record observations. Teachers will be given a record sheet with student names pre-filled, and each observation will take only a few seconds to complete. Given this, and as teachers continually monitor classroom behaviour as part of their daily routine, this approach is considered feasible. Lastly, teachers' reports of classroom behaviour as reported in a similar previous study were shown to be reliable (alpha $=0.85$ ) [18]; however, to the authors' knowledge only one previous study has used such measures. Nonetheless, although the same class teachers who deliver the intervention will also record observations of behaviour, risk of bias is expected to be minimal.

Classroom behaviour at the individual level will be measured by teachers using a tool adopted from the Direct Behaviour Rating Scale [51]. The Direct Behaviour Rating Scale is a hybrid of direct observation and behaviour rating scales. This observation tool requires teachers to indicate for each child, on a scale from $1(0 \%)$ to $10(100 \%)$, the percentage of time that they are on-task, referred to as academically engaged in this tool (i.e. listening to the teacher, writing, looking at instructional materials, etc.) during the observation period. This tool provides a valid measure of 
classroom behaviour, when compared with direct observation ( $r=0.81$ to 0.87 ) [52]. Further, this tool has evidence of reliability $(r=0.91)$ based on data from 617 primary school students obtained from 44 classroom teachers [51].

Behaviour at the whole class level will be measured using a modified version of the Classroom Behaviour and Assets Survey-Teacher which is designed to efficiently provide a snapshot of the teacher's perception of the behaviour of a whole class of students [53]. Teachers will be required to indicate the proportion of the class displaying on-task behaviour (as defined in the individual behaviour assessment tool), during the observation period. Response options include: 0 (0 students), 1 (1-2 students), 2 (a few students), 3 (about a quarter of the class), 4 (about half of the class), 5 (about three quarters of the class), 6 (most of the class), and 7 (all of the class) [53]. Although few tools are available for assessing classroom behaviour at the classroom level, and information on reliability and validity is lacking, a modified version of this tool has been used in a similar study, with evidence of reliability $($ alpha $=0.85)$ [18].

\section{Physical activity}

Waist-worn ActiGraph GT3-X accelerometers (children with parental consent) will be used to provide an objective measure of children's moderate- to vigorous-intensity physical activity across the school day. The ActiGraph accelerometer is commonly used in studies involving children [54] and has documented evidence of validity and reliability for measuring children's physical activity [55]. Accelerometers will be worn during waking hours for seven consecutive days at baseline, mid-intervention (intervention group only), and the end (week 6) of the intervention period. Measures will be taken in the last week of the intervention, rather than post intervention as the intervention is intended to have acute effects.

The accelerometers will be distributed and collected from the child's school at the beginning and end of each 7-day wear period. The researcher will explain about, and fit the monitors to children with parental consent and provide children with an information leaflet to take home to their parents explaining when and how the monitor should be worn and care instructions. Participants' physical activity will be included for analysis if they wear the accelerometer for at least five school hours on at least one school day, as used in similar studies, involving physically active lessons [23]. Freedson cut-points will be used to classify physical activity as moderate- to vigorous-intensity [56]. These cut-points have been shown to accurately classify children's moderate- to vigorous-intensity physical activity $($ ROC-AUC $=0.90$ ) [57]. Data will be collected in 15-s epochs [58] and non-wear time will be defined as 20 min of consecutive zero's, as commonly used in studies involving children [59].

\section{Intervention fidelity}

To assess fidelity of implementation, children will wear accelerometers mid-way through the intervention (week 3 ) as well as during the final week of the intervention period (week 6). Furthermore, teachers will complete a $\log$ of the ACTI-BREAKS that they complete over the intervention period. The researcher (AW) will collect these at the end of every week to ensure teacher fidelity throughout the study. Accelerometer data will be compared with teacher logs of ACTI-BREAKS completed at week 3 and week 6 of the intervention to verify that students were physically active at a moderate intensity for the 5-min ACTI-BREAK duration.

\section{Process evaluation}

Subjective evaluations of the intervention components will also be provided by students and teachers throughout the intervention. During each of weeks 1, 3, and 6 of the intervention, students will be asked to rate three different ACTI-BREAK activities (decided by the classroom teacher), immediately following participation using a 4point Likert scale ranging from 'I hated it' $=1$ to 'I loved $\mathrm{it}^{\prime}=4$. Upon competition of the 6-week programme, students will be asked to complete a questionnaire to rate how they feel about the ACTI-BREAK activities using a 4-point Likert scale with responses ranging from 'strongly disagree' $=1$ to 'strongly agree' $=4$ in the areas of (1) enjoyment, (2) effect on learning and behaviour, (3) ability to do the activities, and (4) preferred duration, intensity, and frequency of activities. For example, 'I enjoyed the ACTI-BREAK programme' and 'I found it easier to concentrate after doing ACTI-BREAK activities'. Students will also have the opportunity to provide additional feedback on the following open ended questions: 'What did you like about the ACTI-BREAK programme?' and 'Was there anything you didn't like about the ACTI-BREAK programme?'

Post-intervention focus groups will also be conducted with students, facilitated by the researcher. The focus groups will be recorded and later transcribed, with participant consent. Specifically, the questions asked will be designed to provide a more in-depth insight into topics covered in the questionnaire. For example, students will write down the names of two of their favourite, and two of their least favourite ACTI-BREAK activities, and then explain what they liked or did not like about the particular ACTI-BREAK, and what they would change.

A one-on-one 30- to 45-min telephone interview will be conducted with the teachers involved in the intervention group, after programme completion. The researcher 
will conduct these interviews which will be recorded and transcribed. The interviews with teachers will be designed to identify barriers and facilitators to implementation of ACTI-BREAKS, as well as strengths and weaknesses of the programme. The following types of questions will be asked, for example: 'Were there any ACTI-BREAKS you thought worked particularly well/ didn't work particularly well?' and 'Was there anything that made it difficult for you/helped you to use the ACTI-BREAK programme?'

\section{Data analysis}

All statistical analysis will be conducted using Stata 14.0. Multilevel mixed-effects linear regression models will be used to assess the impact of group (intervention vs. control) on achievement scores in reading and mathematics, mean per cent of time in on-task behaviour, and physical activity level at the end of the intervention, each adjusted for baseline levels of the corresponding variable and clustering by class. All analyses will control for physical activity levels at baseline. The fixed effect of school will be added to the model to account for the unit of randomisation. All analyses will be stratified by sex. Alpha levels will be set at $p<0.05$. As this is a pilot study, the intervention will not be adequately powered to detect small changes between groups. Instead, trends in associations will be investigated. Analyses will be conducted both on the intention-to-treat approach, and per protocol analysis (using data from fidelity checks).

Process evaluation data from focus groups and interviews will be analysed using Braun and Clarke's six phases of thematic analysis [60]. Codes will be generated, and continually revised throughout the analysis process. Following coding of the transcripts, themes will be identified and defined. These data, along with data obtained from student enjoyment and satisfaction questionnaires, will provide information that can be used to improve the programme for future testing.

\section{Discussion}

The primary aim of this study is to examine the potential efficacy of a classroom-based physical activity programme known as ACTI-BREAK on children's achievement in mathematics and reading. The impact of ACTI-BREAK on children's on-task behaviour and objectively measured school-day physical activity levels will be explored as secondary aims. Given that the programme is designed to be delivered by trained classroom teachers in the 'real-world' context, assessment of feasibility and fidelity will be a key feature of the pilot study.

A strength of this intervention is that it was developed with input and guidance from current primary school teachers to limit discrepancy between evidence and practice observed in previous studies [4]. For example, our interviews with teachers indicated that anything longer than 5 min would be unlikely to be adopted. Many existing active break programmes require active break durations of between 10 and 15 min [19, 21, 24-26]. However, longer duration active breaks may be unlikely to be feasible beyond the study setting [61].

An additional strength of this study is the use of a curriculum-based measure to assess achievement in reading and mathematics. These tools are sensitive to small changes in academic achievement, and can be administered frequently (e.g. weekly) [62, 63]. Many existing studies have had short intervention periods (less than 1 year) and used standardised tests to assess intervention effects on academic achievement $[29,30]$. These tests are designed to be administered at least 1 year apart [32], and, therefore, important intervention effects on academic achievement are unlikely to be observed. The use of a curriculum-based measure in the current study provides a more suitable measure of academic achievement for the 6-week intervention period, making short-term progress in academic achievement more likely to be observed.

In addition to choice of academic outcome measure, the use of an objective measure of physical activity intensity and cluster randomised controlled trial study design are further strengths of this study. To the author's knowledge, one previous active break intervention has used an objective measure of physical activity intensity [18]. However, that study relied on teacher reports of active break implementation in the past week (to compare physical activity levels of implementers vs. non-implementers) and intervention effects on physical activity levels were assessed on a subsample of participants only [18]. Nonetheless, results from that study highlight the potential for active breaks to contribute to increased physical activity across the school day [18].

Results from this study will provide insight into the feasibility of introducing frequent, short, moderateintensity active breaks into classroom routines, given potential challenges in their application. Further, this study will explore whether this approach will provide enhanced benefits on academic-related outcomes, compared with breaks in sitting time.

\section{Limitations}

Given that some of the teachers who participated in the intervention development referred to using active breaks in their classrooms previously, it is possible that some teachers in the control schools may also do active breaks in their classrooms. However, teachers in the intervention development mainly referred to ad-hoc stretches and coordinative exercises (e.g. Brain Gym); thus, any active break activities conducted by teachers in control schools are not likely to be as frequent or intense as those prescribed in the ACTI-BREAK programme. A further potential limitation relates to the use of teacher- 
reported observations of classroom behaviour. These observations will be recorded by the same teachers who will be delivering the intervention and thus have potential for bias. However, to the authors' knowledge, only one previous study has used such measures which were shown to be reliable $($ alpha $=0.85)[18]$.

\section{Conclusions}

This study has the potential to enhance key educational outcomes (e.g. reading and mathematics achievement) which may encourage teachers and school administrators to provide more opportunities for children to be active at school through incorporating short, active breaks into the classroom routine. The ACTI-BREAK programme has been designed to be a time-efficient, feasible and appealing approach to physical activity promotion in schools. This study will assess required teacher time commitment, the potential for the ACTI-BREAK programme to improve academic-related outcomes and physical activity levels, and its acceptability to teachers and students, with the potential for a full-scale efficacy trial in the future.

\section{Trial status}

The trial is currently recruiting.

\section{Additional file}

Additional file 1: Completed SPIRIT Checklist. (DOCX 64 kb)

\section{Acknowledgements}

AW is a recipient of a Postgraduate Scholarship from Deakin University. AT is supported by a National Heart Foundation of Australia Future Leader Fellowship (Award 100046). KDH is supported by an Australian Research Council Future Fellowship (FT130100637) and an Honorary National Heart Foundation of Australia Future Leader Fellowship (100370).

\section{Funding}

None.

\section{Availability of data and materials}

Not applicable.

\section{Authors' contributions}

AW conceived of the study, developed the intervention materials, drafted the manuscript, and is the project manager. AT, HB, and KDH provided substantial contributions to the conception, design, and content of the study, and reviewed and appraised the manuscript. All authors read and approved the final manuscript.

\section{Authors' information}

AW is an experienced primary school teacher, and holds a Master of Public Health from the University of Adelaide.

\section{Ethics approval and consent to participate}

Ethical approval has been attained from Deakin University Human Research Ethics Committee, Melbourne, Australia (2016-020) and the Victorian Department of Education and Training (2016-002962). Principals, teachers, and parents will provide written informed consent.

\section{Consent for publication}

Not applicable.

\section{Competing interests}

The authors declare they have no competing interests

\section{Publisher's Note}

Springer Nature remains neutral with regard to jurisdictional claims in published maps and institutional affiliations.

Received: 29 April 2017 Accepted: 28 August 2017

Published online: 19 September 2017

\section{References}

1. Okely T, Salmon J, Vella S, Cliff D, Timperio A, Tremblay M, Trost S, Shilton T, Hinkley T, Ridgers N, Phillipson L, Hesketh K, Parrish A, Janssen X, Brown M, Emmel J, Marino N. A systematic review to update the Australian physical activity guidelines for children and young people. In: Report prepared for the Australian Government Department of Health. Canberra: Commonwealth of Australia; 2012.

2. Fedewa AL, Ahn S. The effects of physical activity and physical fitness on children's achievement and cognitive outcomes: a meta-analysis. Res Q Exerc Sport. 2011;82(3):521-35.

3. Sibley BA, Etnier JL. The relationship between physical activity and cognition in children: a meta-analysis. Pediatr Exerc Sci. 2003;15:243-56

4. Erwin H, Fedewa A, Beighle A, Ahn S. A quantitative review of physical activity, health, and learning outcomes associated with classroom-based physical activity interventions. J Appl Sch Psychol. 2012;28(1):14-36.

5. Active Healthy Kids Canada. Active Healthy Kids Canada. Are we driving our kids to unhealthy habits? The 2013 Active Healthy Kids Canada Report Card on Physical Activity for Children and Youth. 2013. [26 March 2015]; Available from: http://www.activehealthykids.ca/2013ReportCard/en/. Accessed 18 Aug 2017.

6. Australian Bureau of Statistics. Australian Health Survey: Physical Activity, 20112012201318 March 2015]; Available from: http://www.abs.gov.au/ausstats/abs@. nsf/Latestproducts/462FBA87B642FCA4CA257BAC0015F3CE?opendocument. Accessed 18 Aug 2017.

7. Griffiths $\perp$, Cortina-Boria M, Sera F, Pouliou T, Geraci M, Rich C, Cole TJ, Law C, Joshi H, Ness AR, Jebb SA, Dezateux C. How active are our children? Findings from the Millennium Cohort Study. BMJ Open. 2013;3(8):e002893.

8. Troiano RP, Berrigan D, Dodd KW, Masse LC, Tilert T, McDowell M. Physical activity in the United States measured by accelerometer. Med Sci Sports Exerc. 2008;40(1):181-8.

9. Hotting $\mathrm{K}$, Roder B. Beneficial effects of physical exercise on neuroplasticity and cognition. Neurosci Biobehav Rev. 2013;37(9 Pt B):2243-57.

10. Webster CA, Russ L, Vazou S, Goh TL, Erwin H. Integrating movement in academic classrooms: understanding, applying and advancing the knowledge base. Obes Rev. 2015;16(8):691-701.

11. McMullen J, Kulinna P, Cothran D. Physical activity opportunities during the school day: classroom teachers' perceptions of using activity breaks in the classroom. J Teach Phys Educ. 2014;33(4):511-27.

12. Sherry AP, Pearson N, Clemes SA. The effects of standing desks within the school classroom: a systematic review. Prev Med Rep. 2016;3:338-47.

13. Norris E, Shelton N, Dunsmuir S, Duke-Williams O, Stamatakis E. Physically active lessons as physical activity and educational interventions: a systematic review of methods and results. Prev Med. 2015;72:116-25.

14. Ma JK, Le Mare L, Gurd BJ. Classroom-based high-intensity interval activity improves off-task behaviour in primary school students. Appl Physiol Nutr Metab. 2014;39(12):1332-7.

15. Howie EK, Beets MW, Pate RR. Acute classroom exercise breaks improve ontask behavior in 4th and 5 th grade students: A dose-response. Ment Health and Phys Act. 2014:7(2):65-71.

16. Howie EK, Schatz J, Pate RR. Acute effects of classroom exercise breaks on executive function and math performance: a dose-response study. Res $Q$ Exerc Sport. 2015;86(3):217-24

17. Uhrich TA, Swalm RL. A pilot study of a possible effect from a motor task on reading performance. Percept Mot Skills. 2007;104(3 Pt 1):1035-41.

18. Carlson JA, Engelberg JK, Cain KL, Conway TL, Mignano AM, Bonilla EA, Geremia C, Sallis JF. Implementing classroom physical activity breaks: associations with student physical activity and classroom behavior. Prev Med. 2015:81:67-72.

19. Whitt-Glover MC, Ham SA, Yancey AK. Instant Recess(R): a practical tool for increasing physical activity during the school day. Prog Community Health Partnersh. 2011;5(3):289-97. 
20. Ma JK, Le Mare L, Gurd BJ. Four minutes of in-class high-intensity interval activity improves selective attention in 9- to 11-year olds. Appl Physiol Nutr Metab. 2015;40(3):238-44.

21. Janssen M, Chinapaw MJM, Rauh SP, Toussaint HM, van Mechelen W, Verhagen EALM. A short physical activity break from cognitive tasks increases selective attention in primary school children aged 10-11. Ment Health and Phys Act. 2014;7(3):129-34.

22. Webster CA, Caputi P, Perreault M, Doan R, Doutis Panayiotis P, Weaver RG Elementary classroom teachers' adoption of physical activity promotion in the context of a statewide policy: an innovation diffusion and socioecologic perspective. J Teach Phys Educ. 2013;32(4):419-40.

23. Riley N, Lubans DR, Morgan PJ, Young M. Outcomes and process evaluation of a programme integrating physical activity into the primary school mathematics curriculum: The EASY Minds pilot randomised controlled trial. J Sci Med Sport. 2015;18(6):656-61.

24. Hill L, Williams JHG, Aucott L, Milne J, Thomson J, Greig J, Munro V, MonWilliams M. Exercising attention within the classroom. Dev Med Child Neurol. 2010;52(10):929-34.

25. Hill LJ, Williams JH, Aucott L, Thomson J, Mon-Williams M. How does exercise benefit performance on cognitive tests in primary-school pupils? Dev Med Child Neurol. 2011;53(7):630-5.

26. Wilson AN, Olds T, Lushington K, Petkov J, Dollman J. The impact of 10-min activity breaks outside the classroom on male students' on-task behaviour and sustained attention: a randomised crossover design. Acta Paediatr. 2015;105(4):e181-8.

27. Howie EK, Newman-Norlund RD, Pate RR. Smiles count but minutes matter: responses to classroom exercise breaks. Am J Health Behav. 2014;38(5):681-9.

28. Altenburg TM, Chinapaw MJM, Singh AS. Effects of one versus two bouts of moderate intensity physical activity on selective attention during a school morning in Dutch primary schoolchildren: a randomized controlled trial. J Sci Med Sport. 2016;19(10):820-4.

29. Ahamed Y, MacDonald H, Reed K, Naylor P-J, Liu-Ambrose T, McKay H. School-based physical activity does not compromise children's academic performance. Med Sci Sports Exerc. 2007;39(2):371-6.

30. Katz DL, Cushman D, Reynolds J, Njike V, Treu JA, Walker J, Smith E, Katz C. Putting physical activity where it fits in the school day: preliminary results of the $\mathrm{ABC}$ (Activity Bursts in the Classroom) for fitness program. Prev Chronic Dis. 2010;7(4):A82.

31. Lisahunter R, Abbott D, Ziviani MJ, Cuskelly M. Active kids active minds: a physical activity intervention to promote learning? Asia Pac J Health Sport Phys Educ. 2014;5(2):117-31.

32. Bricker D, Yovanoff $P$, Capt B, Allen D. Use of a Curriculum-Based Measure To Corroborate Eligibility Decisions. J Early Intervention. 2003;26(1):20-30.

33. Barnard M, Van Deventer KJ, Oswald MM. The role of active teaching programmes in academic skills enhancement of grade 2 learners in the Stellenbosch Region. S Afr J Res Sport Phys Educ Recreation. 2014;36(3):1-14.

34. Deno S. The nature and development of curriculum-based measurement. Prev Sch Fail. 1992;36(2):5.

35. Deno SL. Curriculum-based measures: development and perspectives. Assess Eff Interv. 2003:28(3-4):3-12

36. Australian Curriculum Assessment and Reporting Authority. National Assessment Program-Literacy and Numeracy. 2016; Available from: http:// www.nap.edu.au/naplan/naplan.html. Accessed 15 Aug 2017.

37. Wheldall K, Madelaine A. Manual for the Wheldall assessment of reading passages (WARP). Sydney: Multilit Pty Ltd; 2013.

38. Carson V, Salmon J, Arundell L, Ridgers ND, Cerin E, Brown H, Hesketh KD, Ball K, Chinapaw M, Yildirim M, Daly RM, Dunstan DW, Crawford D. Examination of mid-intervention mediating effects on objectively assessed sedentary time among children in the Transform-Us! cluster-randomized controlled trial. Int J Behav Nutr Phys Act. 2013;10:62.

39. State Government of Victoria (Department of Education and Training). Summary Statistics Victorian Schools. 2017. Available from: http://www. education.vic.gov.au/about/department/Pages/factsandfigures.aspx.

40. Australian Bureau of Statistics. Commentary on School Numbers. 2016. Available from: http://www.abs.gov.au/AUSSTATS/abs@.nsf/Lookup/4221. OMain+Features392015?OpenDocument. Accessed 14 Aug 2017.

41. Roberts $C$, Torgerson DJ. Baseline imbalance in randomised controlled trials. Br Med J. 1999;319(7203):185.

42. Michie $S$, Atkins L, West R. The behaviour change wheel: a guide to designing interventions. London: Silverback Publishing; 2014.
43. Bandura A. Social foundations of thought and action : a social cognitive theory. Prentice-Hall series in social learning theory. Englewood Cliffs: Prentice-Hall; 1986. p. c1986.

44. Active Academics. Learning on the move. 2005-2016; Available from: http://www.activeacademics.org/. Accessed 8 Aug 2016.

45. GoNoodle. GoNoodle. 2016. Available from: https://www.gonoodle.com/. Accessed 8 Aug 2016

46. YouTube. YouTube. 2016. Available from: https://www.youtube.com. Accessed 8 Aug 2016

47. Maher MT, Kenny RK, Shields AT, Scales DP, Collins G. Energizers: classroombased physical activities. Raleigh: North Carolina Department of Public Instruction; 2006.

48. Reschly AL, Busch TW, Betts J, Deno SL, Long JD. Curriculum-based measurement oral reading as an indicator of reading achievement: a metaanalysis of the correlational evidence. J Sch Psychol. 2009;47(6):427-69.

49. Wheldall $K$, Madelaine $A$. The development of a passage reading test for the frequent monitoring of performance of low-progress readers. Australasian J Spec Educ. 2006;30(1):72.

50. Westwood PS. One Minute Test of Basic Number Facts. In: Numeracy and learning difficulties: approaches to teaching and assessment. Camberwell: ACER Press; 2000. p. 108

51. Chafouleas SM, Kilgus SP, Jaffery R, Riley-Tillman TC, Welsh M, Christ TJ. Direct behavior rating as a school-based behavior screener for elementary and middle grades. J Sch Psychol. 2013:51:367-85.

52. Riley-Tillman TC, Chafouleas SM, Sassu KA, Chanese JAM, Glazer AD. Examining the agreement of direct behavior ratings and systematic direct observation data for on-task and disruptive behavior. J Posit Behav Interv. 2008;10(2):136-43.

53. Lee SW, Shaftel J, Neaderhiser J, Oeth J. Development and Validation of Instruments to Assess the Behavior and Assets of Students at the Classroom Level. in American Psychological Association Convention Presentation. Toronto: American Psychological Association (APA); 2009.

54. Rowlands AV. Accelerometer assessment of physical activity in children: an update. Pediatr Exerc Sci. 2007;19(3):252-66.

55. Trost SG, Ward DS, Moorehead SM, Watson PD, Riner W, Burke JR. Validity of the computer science and applications (CSA) activity monitor in children. Med Sci Sports Exerc. 1998;30(4):629-33.

56. Freedson P, Pober D, Janz KF. Calibration of accelerometer output for children. Med Sci Sports Exerc. 2005;37(11 Suppl):S523-30.

57. Trost SG, Loprinzi PD, Moore R, Pfeiffer KA. Comparison of accelerometer cut points for predicting activity intensity in youth. Med Sci Sports Exerc. 2011:43(7):1360-8

58. Bailey RC, Olson J, Pepper SL, Porszasz J, Barstow TJ, Cooper DM. The level and tempo of children's physical activities: an observational study. Med Sci Sports Exerc. 1995;27(7):1033-41.

59. Cain KL, Sallis JF, Conway TL, Van Dyck D, Calhoon L. Using accelerometers in youth physical activity studies: a review of methods. J Phys Act Health. 2013;10(3):437-50

60. Braun V, Clarke V. Using thematic analysis in psychology. Qual Res Psychol. 2006:3(2):77-101.

61. Gately P, Curtis C, Hardaker R. An evaluation in UK schools of a classroombased physical activity programme-TAKE 10 ! $\hat{A}^{\circledast}$ : a qualitative analysis of the teachers' perspective. Educ Health. 2013;31(4):72-8.

62. Madelaine A, Wheldall K. Towards a curriculum-based passage reading test for monitoring the performance of low-progress readers using standardised passages: a validity study. Educ Psychol. 1998;18(4):471-8.

63. Madelaine A, Wheldall K. Further progress towards a standardised curriculum-based measure of reading: calibrating a new passage reading test against the New South Wales Basic Skills Test. Educ Psychol. 2002;22(4):461-71. 